\title{
System Characterization Report on the German Aerospace Center (DLR) Earth Sensing Imaging Spectrometer (DESIS)
}

\section{Chapter A of}

System Characterization of Earth Observation Sensors

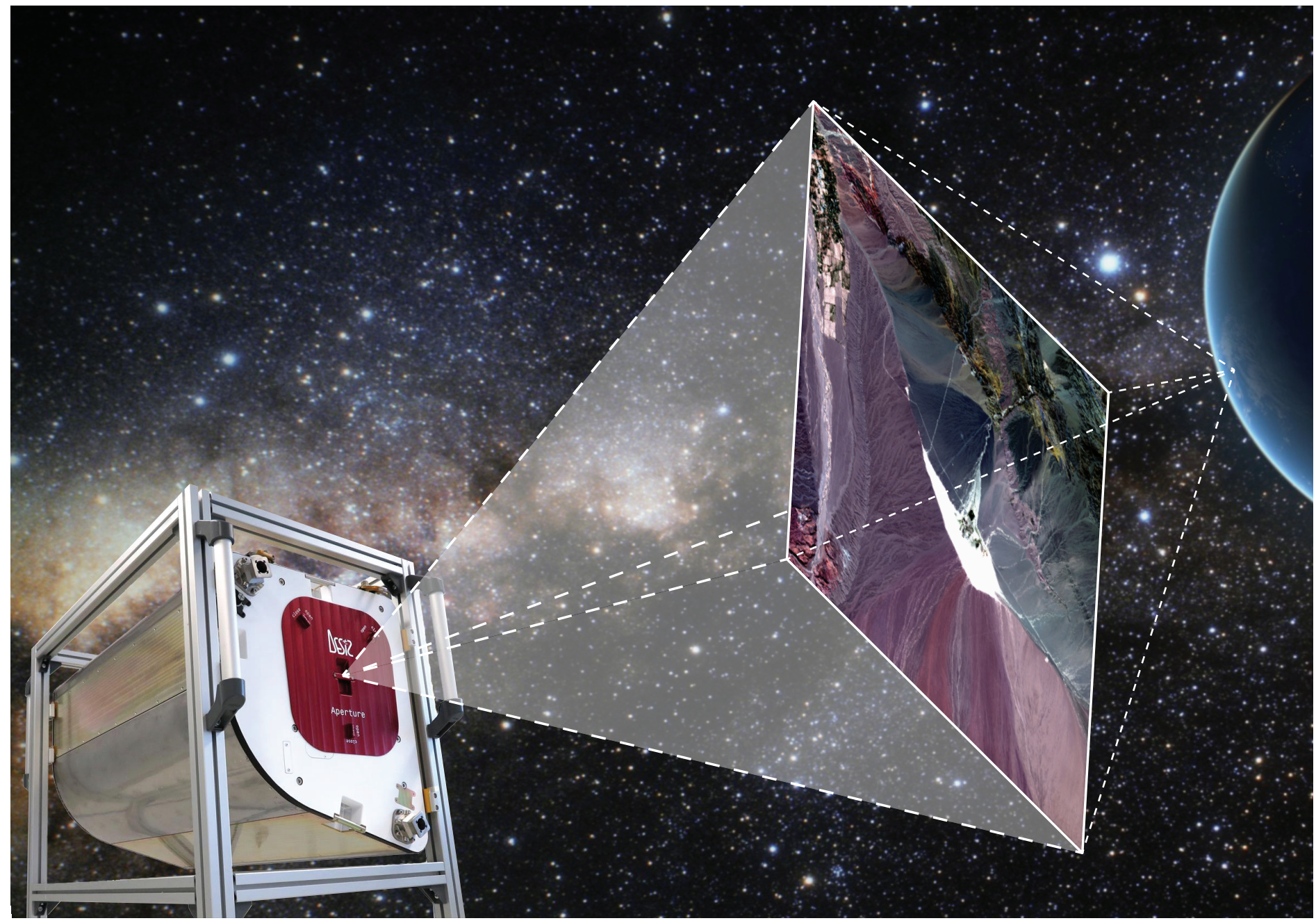

Open-File Report 2021-1030-A 
Cover: Photograph showing the DESIS hyperspectral instrument onboard the International Space Station, launched in June 2018. Photograph courtesy of DLR, licensed under the Creative Commons Attribution-Share Alike 3.0 Unported license. Imagery from the DESIS hyperspectral sensor. Image courtesy of DLR/Teledyne Brown Engineering, used with permission. Image of Earth in space. Image licensed under the Creative Commons Universal Public Domain Dedication 1.0 license. 


\section{System Characterization Report on the German Aerospace Center (DLR) Earth Sensing Imaging Spectrometer (DESIS)}

By Mahesh Shrestha, ${ }^{1}$ Aparajithan Sampath, ${ }^{1}$ Shankar N. Ramaseri Chandra, Jon B. Christopherson, ${ }^{1}$ Jerad Shaw, ${ }^{1}$ and Cody Anderson ${ }^{2}$

Chapter A of

System Characterization of Earth Observation Sensors

Compiled by Shankar N. Ramaseri Chandra'

${ }^{1}$ KBR, Inc., under contract to the U.S. Geological Survey.

${ }^{2}$ U.S. Geological Survey.

Open-File Report 2021-1030-A 


\section{U.S. Geological Survey, Reston, Virginia: 2021}

For more information on the USGS - the Federal source for science about the Earth, its natural and living resources, natural hazards, and the environment—visit https://www.usgs.gov or call 1-888-ASK-USGS.

For an overview of USGS information products, including maps, imagery, and publications, visit https://store.usgs.gov/.

Any use of trade, firm, or product names is for descriptive purposes only and does not imply endorsement by the U.S. Government.

Although this information product, for the most part, is in the public domain, it also may contain copyrighted materials as noted in the text. Permission to reproduce copyrighted items must be secured from the copyright owner.

Suggested citation:

Shrestha, M., Sampath, A., Ramaseri Chandra, S.N., Christopherson, J.B., Shaw, J., and Anderson, C., 2021, System characterization report on the German Aerospace Center (DLR) Earth Sensing Imaging Spectrometer (DESIS),

chap. A of Ramaseri Chandra, S.N., comp., System characterization of Earth observation sensors: U.S. Geological Survey Open-File Report 2021-1030, 9 p., https://doi.org/10.3133/ofr20211030A.

ISSN 2331-1258 (online) 


\section{Contents}

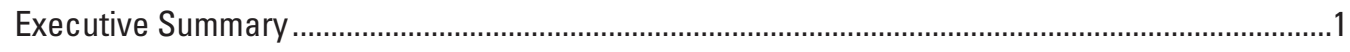

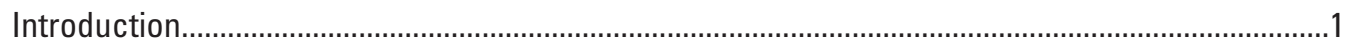

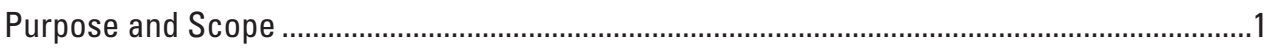

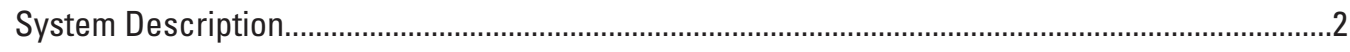

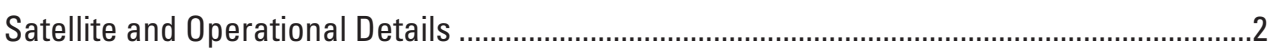

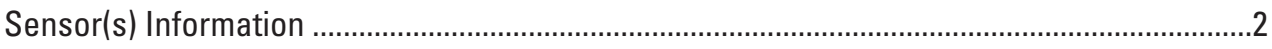

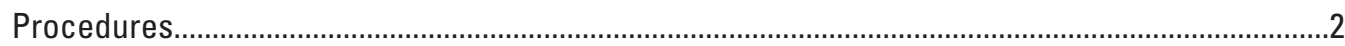

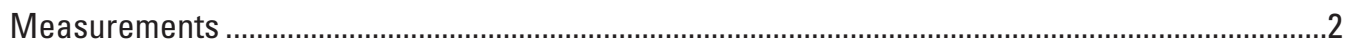

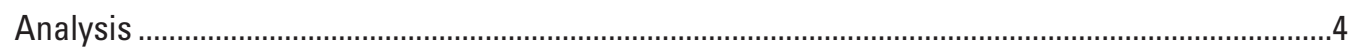

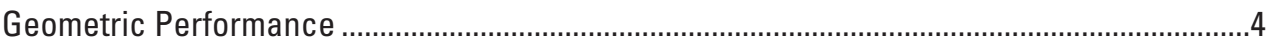

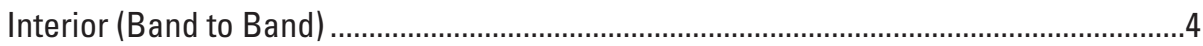

Exterior (Geometric Location Accuracy) .........................................................................

Radiometric Performance .......................................................................................................

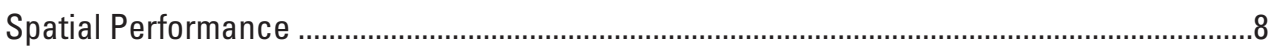

Summary and Conclusions......................................................................................................

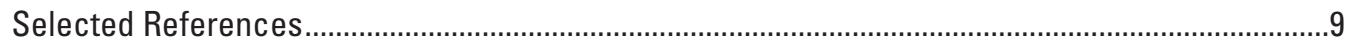

\section{Figures}

1. Graph showing DESIS spectral response ……….........................................................

2. Graph showing band-to-band alignment analysis results for reference band $130 \ldots \ldots \ldots . . .5$

3. Graph showing relative geometric error comparison for the Landsat 8 Operational Land Imager and DESIS ..........................................................................6

4. Graph showing relative geometric error comparison for Landsat 8 Operational Land Imager and DESIS after bias removal ................................................................

5. Graph showing Top of Atmosphere reflectance comparison for Landsat 8 Operational Land Imager and DESIS ..........................................................................

6. Graphs showing Top of Atmosphere reflectance comparison for Landsat 8

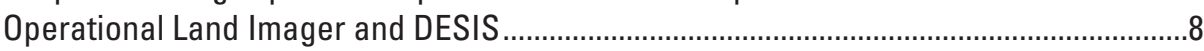

\section{Tables}

1. Satellite and operational details for DESIS ……............................................................

2. Imaging sensor details for DESIS ................................................................................

3. U.S. Geological Survey measurement results ...............................................................

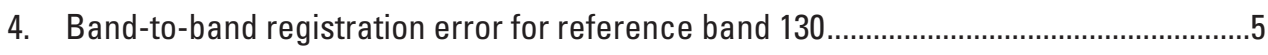

5. Geometric error relative to the Landsat 8 Operational Land Imager ..................................

6. Top of Atmosphere reflectance comparison against Landsat 80 perational

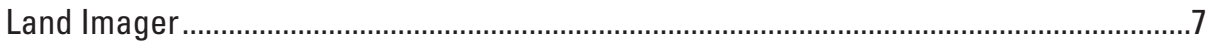

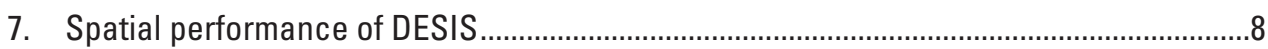




\section{Conversion Factors}

International System of Units to U.S. customary units

\begin{tabular}{lll}
\hline \multicolumn{1}{c}{ Multiply } & \multicolumn{1}{c}{ By } & To obtain \\
\hline & \multicolumn{1}{c}{ Length } & \\
\hline nanometer $(\mathrm{nm})$ & $3.93701 \times 10^{-8}$ & inch (in.) \\
meter $(\mathrm{m})$ & 3.281 & foot (ft) \\
meter $(\mathrm{m})$ & 1.094 & yard (yd) \\
kilometer $(\mathrm{km})$ & 0.6214 & mile (mi) \\
\hline
\end{tabular}

\section{Abbreviations}

DESIS DLR Earth Sensing Imaging Spectrometer

DLR German Aerospace Center

ECCOE EROS Cal/Val Center of Excellence

EROS Earth Resources Observation and Science

GSD ground sample distance

IAS Image Assessment System

OLI Operational Land Imager

USGS U.S. Geological Survey 


\title{
System Characterization Report on the German Aerospace Center (DLR) Earth Sensing Imaging Spectrometer (DESIS)
}

\author{
By Mahesh Shrestha, ${ }^{1}$ Aparajithan Sampath, ${ }^{1}$ Shankar N. Ramaseri Chandra, ${ }^{1}$ Jon B. Christopherson, Jerad \\ Shaw, and Cody Anderson ${ }^{2}$
}

\section{Executive Summary}

This report addresses system characterization of the German Aerospace Center (DLR) Earth Sensing Imaging Spectrometer (DESIS) and is part of a series of system characterization reports produced and delivered by the U.S. Geological Survey Earth Resources Observation and Science Cal/Val Center of Excellence. These reports present the methodology and procedures for characterization and the technical and operational information about the specific sensing system being evaluated. These reports also provide a description of data measurements, data retention practices, and data analysis results and provide system characterization conclusions.

In partnership with Teledyne Brown Engineering, DLR built the DESIS hyperspectral instrument, which Teledyne Brown Engineering then integrated onto its International Space Station-based imaging platform, the Multi-User System for Earth Sensing. DLR developed the processing software and, together with Innovative Imaging and Research, completes the validation and calibration of the data products. DESIS was launched in 2018, and the data are used for scientific research in atmospheric physics and Earth sciences. The DESIS sensor contributes to the scientific and commercial utilization of the International Space Station and helps to further hyperspectral remote sensing technologies for future satellites. More information on DLR satellites and sensors is included within the "2020 Joint Agency Commercial Imagery Evaluation-Remote Sensing Satellite Compendium" and at https://www.dlr.de/DE/Home/home_node.html.

The Earth Resources Observation and Science Cal/Val Center of Excellence system characterization team completed data analyses to characterize the geometric (interior and exterior), radiometric, and spatial performances. Results of these analyses indicate that DESIS has an interior geometric performance of less than a 3.30-meter (less than 0.11 pixel) root mean square error in band-to-band registration, an exterior geometric performance in the range of a 2.40 - $(0.08$ pixel $)$ to 17.40-meter ( 0.58 pixel) offset in comparison to the Landsat 8

${ }^{1}$ KBR, Inc., under contract to the U.S. Geological Survey.

${ }^{2}$ U.S. Geological Survey.
Operational Land Imager, a radiometric performance in the range of -0.013 to 1.011 (offset and slope), and a spatial performance for band 130 of 1.5 pixels at full width at half maximum, with a modulation transfer function at a Nyquist frequency of 0.167 .

\section{Introduction}

The German Aerospace Center (DLR) Earth Sensing Imaging Spectrometer (DESIS) sensor was launched from Cape Canaveral, Florida, on June 29, 2018, as part of the SpaceX CRS-15 logistics flight to the International Space Station. DESIS was placed in the Multi-User System for Earth Sensing facility on the International Space Station for environmental monitoring. DESIS is a hyperspectral imaging spectrometer with as many as 235 bands built and designed by DLR and Teledyne Brown Engineering. DESIS data are commercially available through Teledyne Brown Engineering. For more information or acquisition of DESIS data and products, please visit https://tbe.com/geospatial/data-products.

The data analysis results provided within this report have been derived from approved Joint Agency Commercial Imagery Evaluation processes and procedures. The Joint Agency Commercial Imagery Evaluation (https://www .usgs.gov/core-science-systems/eros/calval/jacie) was formed to leverage resources from several Federal agencies for the characterization of remote sensing data and to share those results across the remote sensing community.

\section{Purpose and Scope}

The purpose of this report is to describe the specific sensor or sensing system, test its performance in three categories, complete related data analyses to quantify these performances, and report the results in a standardized document. In this chapter, the DESIS sensor is described. The performance testing of the system is limited to geometric, radiometric, and spatial. The scope of the geometric assessment is limited to testing the interior alignments of spectral bands against each other, and the exterior alignment is tested in reference to the 
Landsat 8 Operational Land Imager (OLI). The information on the Landsat $8 \mathrm{OLI}$ is provided at https://www.usgs.gov/corescience-systems/nli/landsat/landsat-8.

The U.S. Geological Survey (USGS) Earth Resources Observation and Science (EROS) Cal/Val Center of Excellence (ECCOE) project, and the associated system characterization process used for this assessment, follows the USGS Fundamental Science Practices, which include maintaining data, information, and documentation needed to reproduce and validate the scientific analysis documented in this report. Additional information and guidance about Fundamental Science Practices and related resource information of interest to the public are available at https://www .usgs.gov/about/organization/science-support/office-sciencequality-and-integrity/fundamental-science-practices. To obtain additional information related to this report, please contact the ECCOE at eccoe@usgs.gov.

\section{System Description}

This section describes the satellite and operational details and provides information about DESIS.

\section{Satellite and Operational Details}

DESIS is the solar reflective imager installed on the International Space Station. DESIS has 235 channels, which measure energy from 400 to 1,000 nanometers (nm). DESIS has a swath width of 30 kilometers $(\mathrm{km}) \times 30 \mathrm{~km}$ and ground sample distance (GSD) of 30 meters (m). Key satellite and operational details of DESIS are presented in table 1.

\section{Sensor(s) Information}

Imaging sensor details for DESIS are provided in table 2. DESIS spectral responses at the selected wavelength range (that is, $400-460 \mathrm{~nm}$ ) are shown in figure 1 .

\section{Procedures}

ECCOE has established standard processes to identify Earth observing systems of interest and to assess the geometric, radiometric, and spatial qualities of data products from these systems. The process steps are as follows:

- system identification and investigation to learn the general specifications of the satellite and its sensor(s);

- data receipt and initial inspection to understand the characteristics and any overt flaws in the data product so that it may be further analyzed;

- geometry characterization, including interior geometric orientation measuring the relative alignment of spectral bands and exterior geometric orientation measuring how well the georeferenced pixels within the image are aligned to a known reference;

- radiometry characterization, including assessing how well the data product correlates with a known reference and, when possible, assessing the signal-to-noise ratio; and

- spatial characterization, assessing the two-dimensional fidelity of the image pixels to their projected GSD.

Data analysis and test results are maintained at the USGS EROS Center by the ECCOE project.

\section{Measurements}

The observed USGS measurements are listed in table 3. Physical error, in meters, is calculated by the GSD $(30 \mathrm{~m})$ multiplied by the pixel error. Details about the methodologies used are outlined in the "Analysis" section. 
Table 1. Satellite and operational details for DESIS.

[DESIS, German Aerospace Center (DLR) Earth Sensing Imaging Spectrometer; m, meter; mm, millimeter; kg, kilogram; nm, nanometer; ${ }^{\circ}$, degree; N, north; S, south; \pm , plus or minus; km, kilometer; lat., latitude; NASA, National Aeronautics and Space Administration]

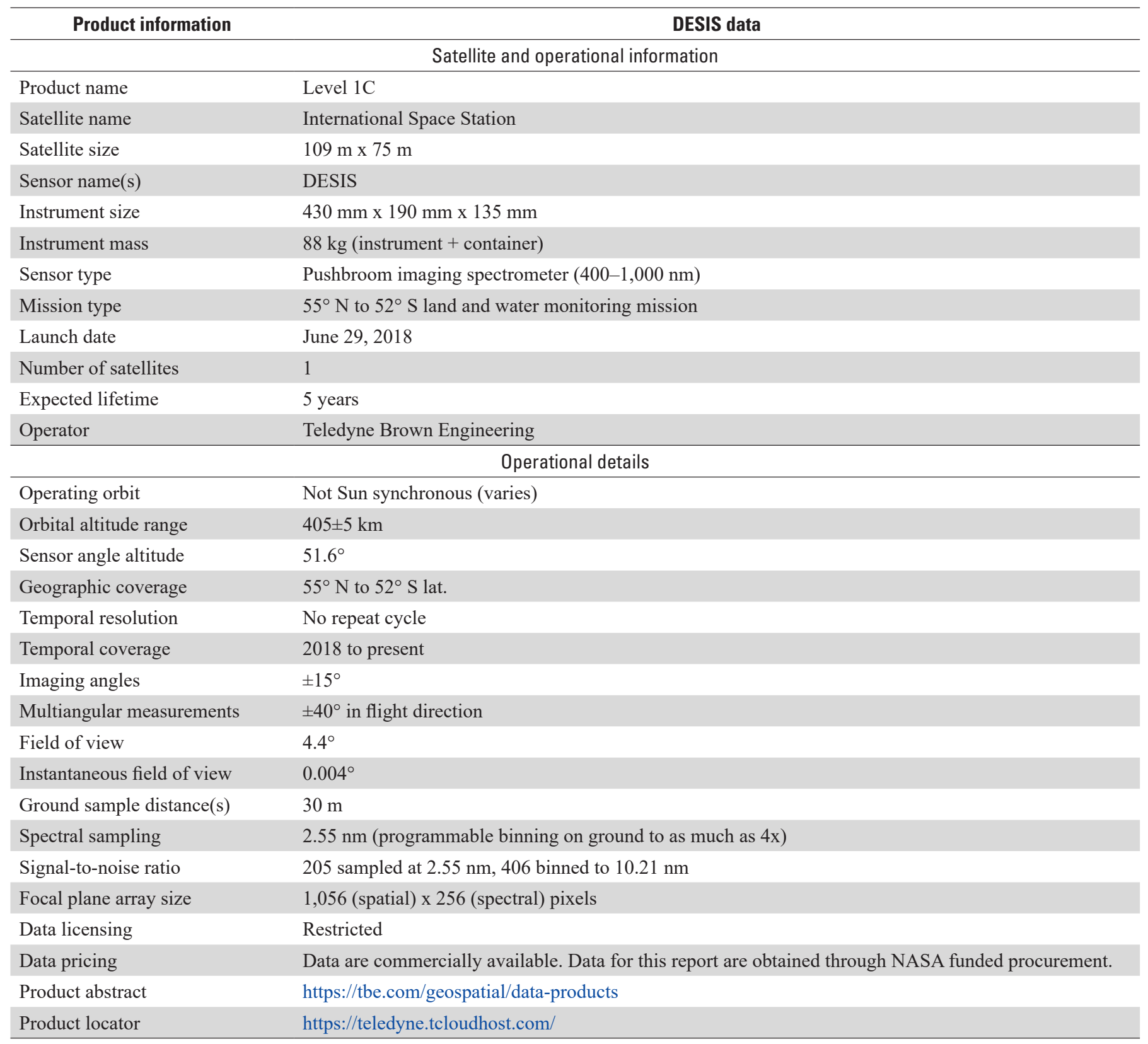

Table 2. Imaging sensor details for DESIS.

[The German Aerospace Center (DLR) Earth Sensing Imaging Spectrometer (DESIS) has a swath width of 30 kilometers; $\mu \mathrm{m}$, micrometer; m, meter]

\begin{tabular}{|c|c|c|c|c|}
\hline \multirow[b]{2}{*}{ Spectral band(s) details } & \multicolumn{4}{|c|}{ DESIS } \\
\hline & Lower band $(\mu \mathrm{m})$ & Upper band $(\mu \mathrm{m})$ & $\begin{array}{c}\text { Radiometric } \\
\text { resolution (bits) }\end{array}$ & $\begin{array}{c}\text { Ground sample } \\
\text { distance }(\mathrm{m})\end{array}$ \\
\hline
\end{tabular}




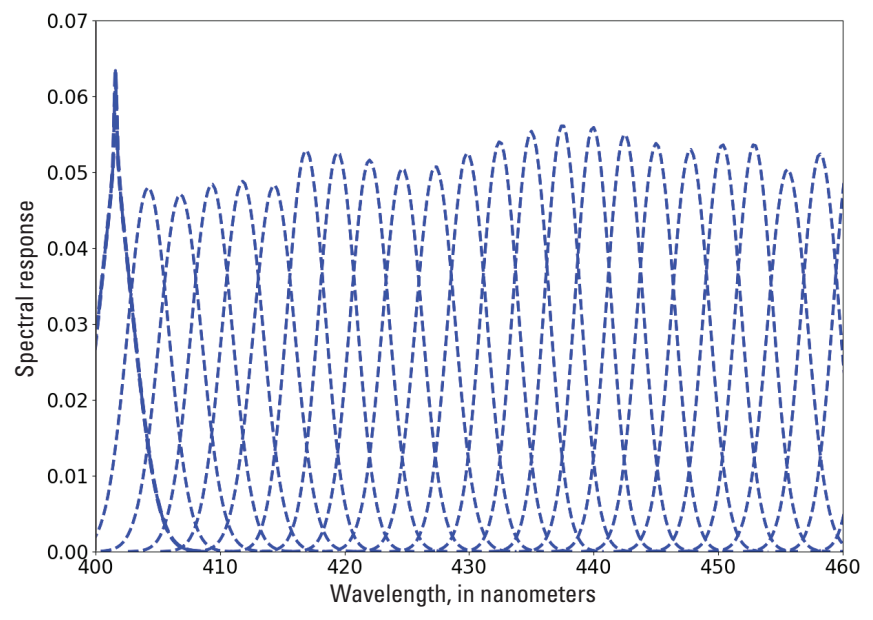

Figure 1. DESIS spectral response. [DESIS, German Aerospace Center (DLR) Earth Sensing Imaging Spectrometer]

\section{Analysis}

This section of the report describes the geometric, radiometric, and spatial performance of DESIS.

\section{Geometric Performance}

Geometric performance is assessed using band-to-band analysis (interior) and geometric location accuracy (exterior). Band-to-band (interior) analysis was completed by choosing one DESIS band as a reference and analyzing alignment of other bands with respect to the reference band. Geometric location accuracy (exterior) geometric performance was completed by comparing the DESIS band with the corresponding Landsat 8 OLI band.

\section{Interior (Band to Band)}

The band-to-band alignment analysis was completed using the Landsat Image Assessment System (IAS) software on an image obtained over Baotou, China. For this analysis and for the ease of reporting, band $130(725 \mathrm{~nm})$ was selected as the reference image. This band was chosen because it is within the red channel, which is known to correlate well with other bands, and because the band is in the middle of the focal plane. Each band of the DESIS image was considered a separate image and compared against the reference band image using the IAS. The pattern shown in figure 2 reveals that there is a slight misalignment between the bands. The pattern indicates that band misalignment is greater moving away from the reference band (band 130). This pattern is visible when any other band is considered as the reference band as well.

Maximum and minimum root mean square error misalignment when compared with band 130 is listed in table 4 with results represented in pixels at a 30-m GSD. These numbers are consistent with tests completed on other DESIS images. The issue of band offset is caused by the use of a rolling shutter, as confirmed by DESIS. More details are documented in Alonso and others (2019). Together, the interior and

Table 3. U.S. Geological Survey measurement results.

[USGS, U.S. Geological Survey; <, less than; m, meter; RMSE, root mean square error; DESIS, German Aerospace Center (DLR) Earth Sensing Imaging Spectrometer; L8 OLI, Landsat 8 Operational Land Imager]

\begin{tabular}{lc}
\hline \multicolumn{1}{c}{ Description of product } & Top of Atmosphere reflectance \\
\hline & USGS measurement results \\
\hline Interior (band-to-band) & Geometric performance (easting, northing), in meters (pixels) \\
Exterior (geometric location accuracy) & All 235 bands were well aligned: $<3.30 \mathrm{~m}(<0.11$ pixel RMSE) \\
& Mean: $3.90 \mathrm{~m}(0.13), 2.40 \mathrm{~m}(0.08)$ \\
& RMSE: $15.90 \mathrm{~m}(0.53), 17.40 \mathrm{~m}(0.58)$ \\
\hline Radiometric evaluation (linear regression- - & Radiometric performance (offset, slope) \\
DESIS versus L8 OLI reflectance) & Coastal aerosol band (offset, slope): $0.002,0.958$ \\
& Blue band (offset, slope): $-0.002,0.978$ \\
& Green band (offset, slope): $-0.007,0.989$ \\
& Red band (offset, slope): $-0.011,1.011$ \\
& Near-infrared band (offset, slope): $-0.013,1.008$ \\
\hline Spatial performance measurement & Spatial performance \\
& Band $130:$ full width at half maximum $=1.5$ pixels; modulation transfer function at \\
& Nyquist $=0.167$ \\
\hline USGS noted artifacts/quality issues & Known artifacts and quality issues \\
& For interior geometric analysis (band to band), there is a systematic error because of \\
\end{tabular}




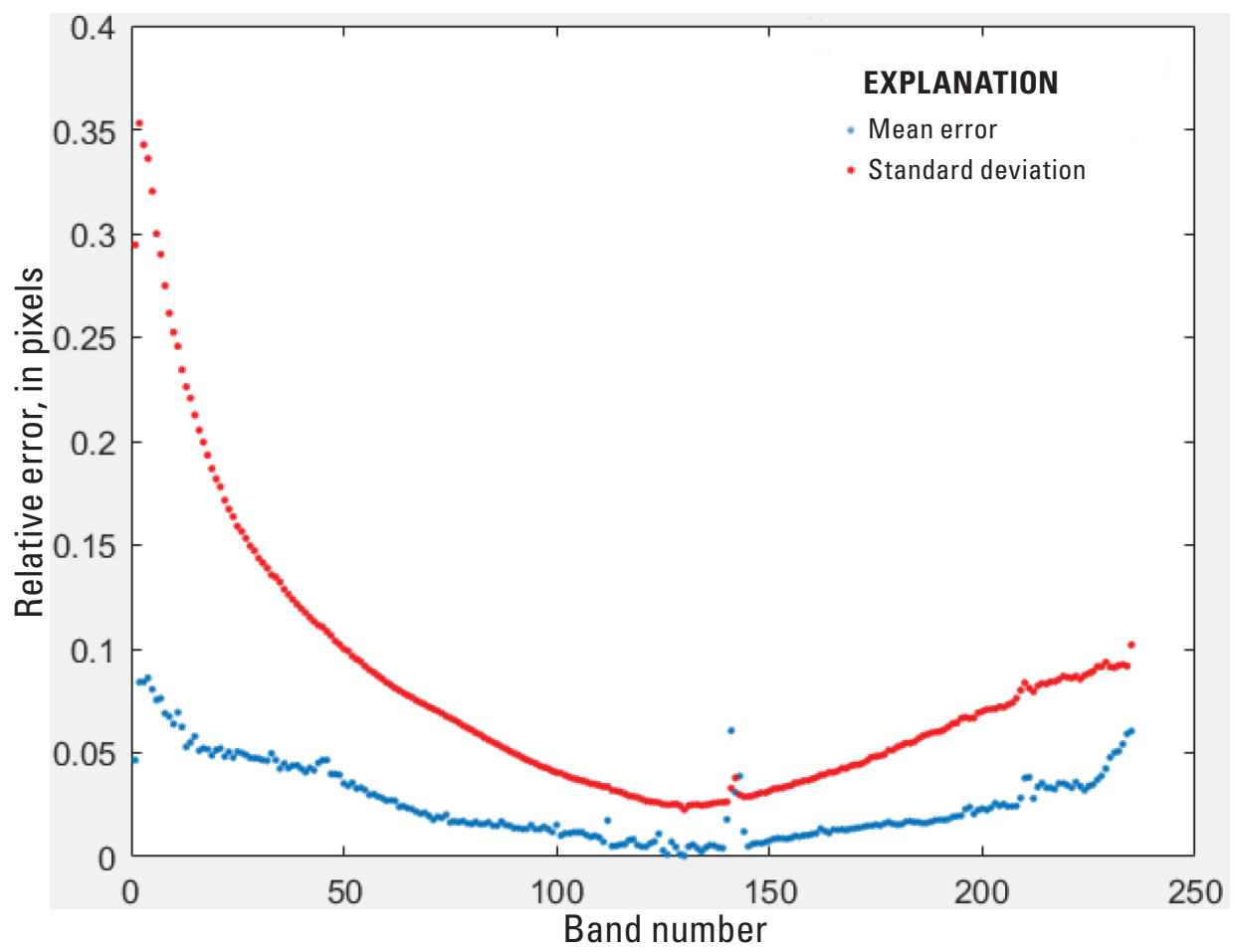

Figure 2. Band-to-band alignment analysis results for reference band 130.

Table 4. Band-to-band registration error for reference band 130 .

[RMSE, root mean square error]

\begin{tabular}{lcc}
\hline Reference band-Band $\mathbf{1 3 0}$ & $\begin{array}{c}\text { Maximum, } \\
\text { in pixels }\end{array}$ & $\begin{array}{c}\text { Minimum, } \\
\text { in pixels }\end{array}$ \\
\hline RMSE (easting) & 0.10 & -0.10 \\
RMSE (northing) & 0.10 & 0.00 \\
\hline
\end{tabular}

exterior geometric analysis results, as reported in this section and the "Exterior (Geometric Location Accuracy)" section, provide a comprehensive assessment of geometric accuracy.

\section{Exterior (Geometric Location Accuracy)}

The geometric location accuracy analysis was completed using the Landsat IAS software on an image obtained over Baotou, China. For this analysis, DESIS band 130 (725 nm) was compared against Landsat 8 OLI band 4 , which has a control uncertainty of $8 \mathrm{~m}$. The mean error and root mean square error results are provided in table 5; results are represented in pixels at a 30-m GSD. A geometric error vector map showing the directional shift and relative magnitude of the shift, when compared with the Landsat 8 OLI, is provided in figure 3. Results after removal of the geometric bias are shown in figure 4. Circular errors 90 and 95 represents the radius of the circle such that there is a 90-percent and 95-percent probability that the error lies within the circle, respectively.

Table 5. Geometric error relative to the Landsat 8 Operational Land Imager.

[ID, identifier; RMSE, root mean square error; $\mathrm{m}$, meter]

\begin{tabular}{|c|c|c|c|c|}
\hline Scene ID & Mean error (easting) & Mean error (northing) & RMSE (easting) & RMSE (northing) \\
\hline $\begin{array}{l}\text { DESIS-HSI-L1C- } \\
\text { DT2019021801_00 } \\
\text { 1-20190218T095150-V0210- } \\
\text { SPECTRAL IMAGE }\end{array}$ & $\begin{array}{l}0.13 \text { pixel } \\
(3.90 \mathrm{~m})\end{array}$ & $\begin{array}{l}0.08 \text { pixel } \\
(2.40 \mathrm{~m})\end{array}$ & $\begin{array}{l}0.53 \text { pixel } \\
(15.90 \mathrm{~m})\end{array}$ & $\begin{array}{l}0.58 \text { pixel } \\
(17.64 \mathrm{~m})\end{array}$ \\
\hline
\end{tabular}



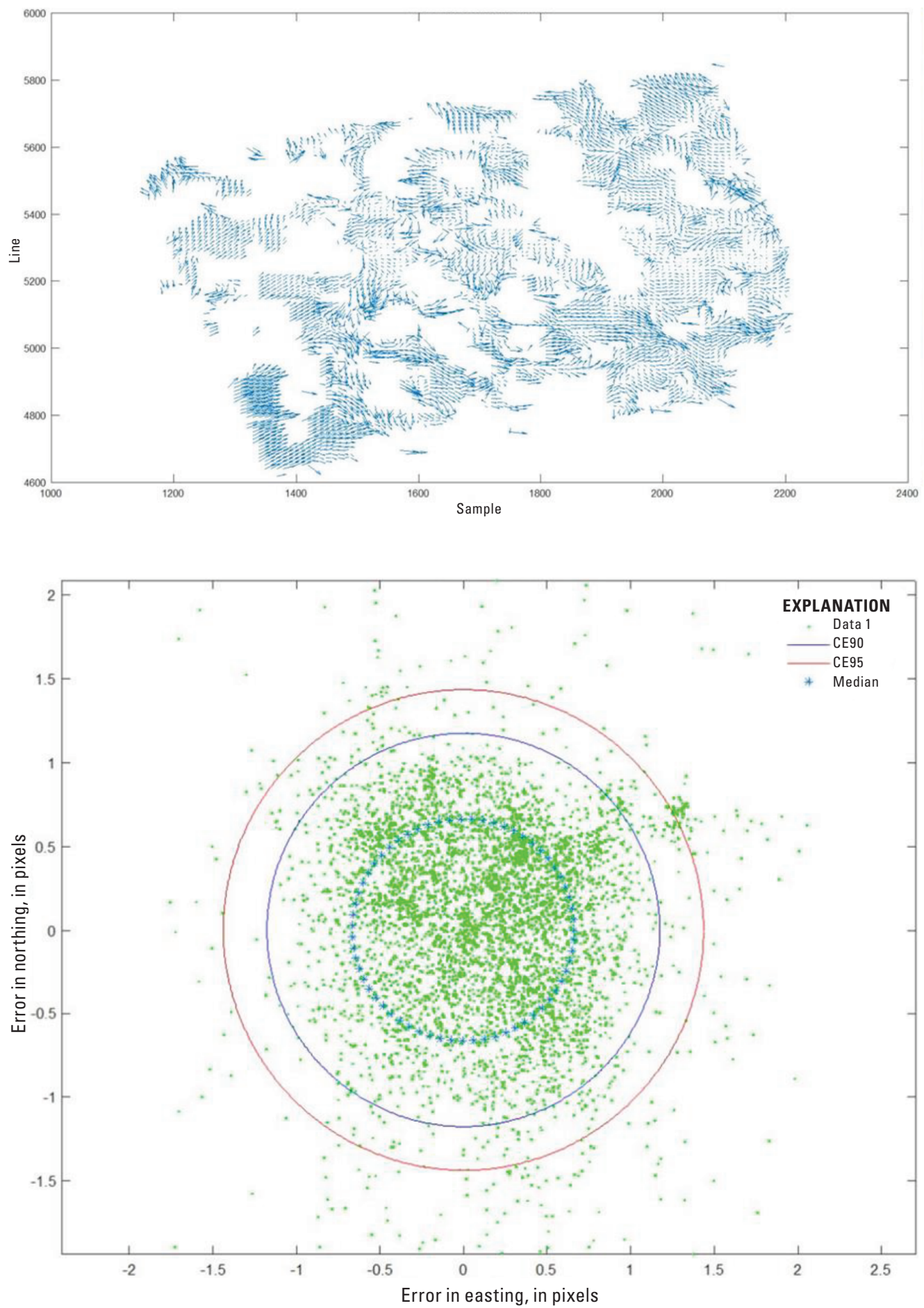

Figure 3. Relative geometric error comparison for the Landsat 8 Operational Land Imager and DESIS. [DESIS, German Aerospace Center (DLR) Earth Sensing Imaging Spectrometer]

Figure 4. Relative geometric error comparison for Landsat 8 Operational Land Imager and DESIS after bias removal. [DESIS, German Aerospace Center (DLR) Earth Sensing Imaging Spectrometer; data1, data point; CE90, circular error 90; CE95, circular error 95] 


\section{Radiometric Performance}

Radiometric performance was evaluated using a linear regression. For this analysis, cloud-free homogeneous regions of interest were selected within three coincident scenes between Landsat 8 OLI and DESIS and cross comparisons were completed with the Landsat 8 OLI as the reference sensor. The three Pseudo Invariant Calibration Sites selected were Barreal Blanco (Argentina; scene identifier DESIS-HSI-L1C-DT0294807348_002-20190312T151733V0206-SPECTRAL_IMAGE), Libya 2 (scene identifier DESIS-HSI-L1C-DT2018101004_006-20181010T183546V0206-SPECTRAL IMAGE), and White Sands (United States; scene identifier DESIS-HSI-L1C-DT2018120802_00 2-20181208T101023-V0206-SPECTRAL_IMAGE). Pseudo Invariant Calibration Sites are the location on Earth surface which are stable over time. The scatterplot in figure 5 is drawn so that the y-axis is the reference sensor and the $\mathrm{x}$-axis is the comparison sensor; thus, the linear regression represents Top of Atmosphere reflectance relative to that of the reference sensor. Ideally, the slope should be near unity and the offset should be near zero; for example, if the slope is less than unity, that means the comparison sensor tends to overestimate Top of Atmosphere reflectance compared to the reference sensor.

Statistical Top of Atmosphere reflectance comparison results are listed in table 6. A graphical Top of Atmosphere reflectance comparison between Landsat 8 OLI and a representative DESIS near-infrared band is shown in figure 5 . Graphical Top of Atmosphere reflectance comparisons between Landsat 8 OLI and representative coastal aerosol, blue, green, and red DESIS bands are shown in figure 6.

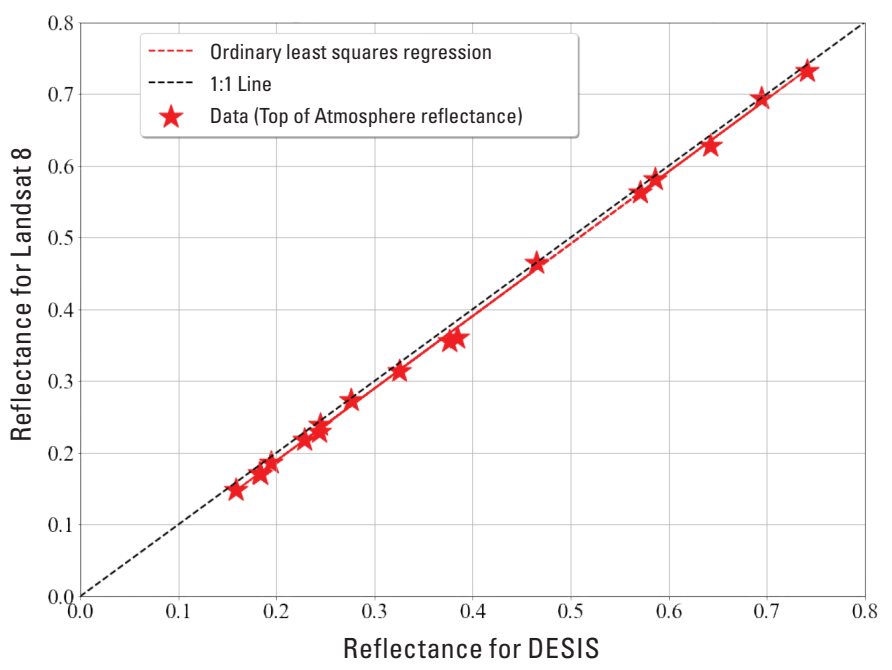

Figure 5. Top of Atmosphere reflectance comparison for Landsat 8 Operational Land Imager and DESIS (near infrared). [DESIS, German Aerospace Center (DLR) Earth Sensing Imaging Spectrometer]

Table 6. Top of Atmosphere reflectance comparison against Landsat 8 Operational Land Imager.

[The scene identifiers for this dataset are DESIS-HSI-L1C-DT0294807348_002-20190312T151733-V0206-SPECTRAL_IMAGE, DESIS-HSI-L1CDT2018101004_006-20181010T183546-V0206-SPECTRAL_IMAGE, and DESIS-HSI-L1C-DT2018120802_002-20181208T101023-V0206SPECTRAL_IMAGE; NIR, near infrared; \%, percent; $R^{2}$, coefficient of determination]

\begin{tabular}{|c|c|c|c|c|c|}
\hline Statistics & Coastal aerosol band & Blue band & Green band & Red band & NIR band \\
\hline Uncertainty (\%) & 4.06 & 2.63 & 2.43 & 2.61 & 3.36 \\
\hline$R^{2}$ & 0.99 & 0.99 & 0.99 & 0.99 & 0.99 \\
\hline Slope & 0.958 & 0.978 & 0.989 & 1.011 & 1.008 \\
\hline
\end{tabular}



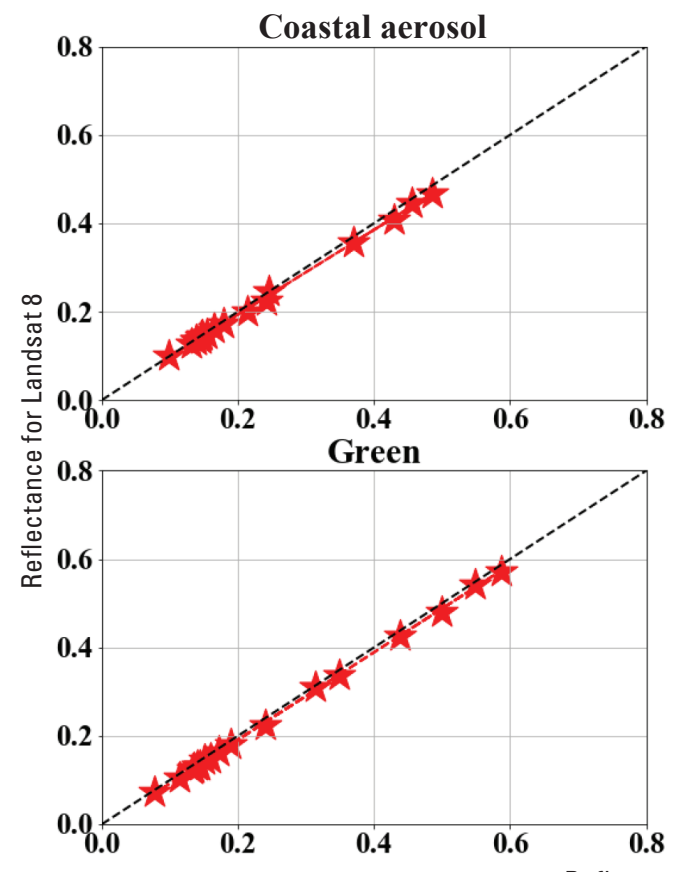

Reflectance for DESIS

\section{Spatial Performance}

The spatial performance characterization of the DESIS system was carried out by analyzing band 130 data over agricultural fields that have inclined edges (with respect to the cardinal directions). The process was carried out using the image quality estimation methods based on Helder and others (2003). Full width at half maximum and modulation transfer function at Nyquist frequency analysis outputs are listed in table 7.

Table 7. Spatial performance of DESIS.

[DESIS, German Aerospace Center (DLR) Earth Sensing Imaging Spectrometer; FWHM, full width at half maximum; MTF, modulation transfer function]

\begin{tabular}{lcc}
\hline Spatial analysis & FWHM & MTF at Nyquist \\
\hline Band 130 & 1.5 pixels & 0.167 \\
\hline
\end{tabular}

\section{Summary and Conclusions}

This report summarizes the sensor performance of the German Aerospace Center (DLR) Earth Sensing Imaging Spectrometer (DESIS) system based on the U.S. Geological Survey Earth Resources Observation and Science Cal/Val Center of Excellence (ECCOE) system characterization process. In summary, we have determined that this sensor provides an interior geometric performance of less than 3.30 meters (less than 0.11 pixel), an exterior geometric performance of 2.40 ( 0.08 pixel) to 17.40 meters ( 0.58 pixel $)$, a radiometric performance of -0.013 to 1.011 (offset and slope), and a spatial performance of 1.5 pixels at full width at half maximum, with a modulation transfer function at a Nyquist frequency of 0.167 .

During DESIS system characterization, the ECCOE system characterization team followed characterization procedures that are standardized across several sensors and remote sensing systems under evaluation; however, these procedures are customized to fit the individual sensor, as was done with DESIS. The team has acquired and retained the data, defined proper testing methodologies, carried out comparative tests against specific references, recorded measurements, completed data analyses, and quantified sensor performance accordingly. The team has retained all data, measurements, and methods. This is key to ensure that all data and measurements are archived and accessible and that the performance results are reproducible.

The ECCOE project and associated Joint Agency Commercial Imagery Evaluation partners are always interested in reviewing sensor and remote sensing application assessments and would like to see and discuss information on similar data and product assessments and reviews. If you would like to discuss system characterization with the U.S. Geological Survey ECCOE and (or) the Joint Agency Commercial Imagery Evaluation team, please email us at eccoe@usgs.gov. 


\section{Selected References}

Alonso, K., Bachmann, M., Burch, K., Carmona, E., Cerra, D., de los Reyes, R., Dietrich, D., Heiden, U., Hölderlin, A., Ickes, J., Knodt, U., Krutz, D., Lester, H., Müller, R., Pagnutti, M., Reinartz, P., Richter, R., Ryan, R., Sebastian, I., and Tegler, M., 2019, Data products, quality and validation of the DLR Earth Sensing Imaging Spectrometer (DESIS): Sensors (Basel), v. 19, no. 20, 4471. [Also available at https://doi.org/10.3390/s19204471.]

DLR, 2021, DESIS mission: DLR web page, accessed May 2020 at https://www.dlr.de/eoc/desktopdefault.aspx/ tabid-13614.

ESA, 2020, eoPortal Directory: ESA web page, accessed May 2020 at https://directory.eoportal.org/web/eoportal/satellitemissions/content/-/article/iss-muses.

Helder, D., Choi, T., and Rangaswamy, M., 2003, In-flight characterization of spatial quality using point spread functions: ISPRS International Workshop on Radiometric and Geometric Calibration, Gulfport, Miss., December 2-5, 38-slide presentation, accessed May 2020 at https://www. isprs.org/proceedings/2003/isprs_ceos_workshop/ Documents/Helder/Helder.ppt.
Krutz, D., Müller, R., Knodt, U., Günther, B., Walter, I., Sebastian, I., Säuberlich, T., Reulke, R., Carmona, E., Eckardt, A., Venus, H., Fischer, C., Zender, B., Arloth, S., Lieder, M., Neidhardt, M., Grote, U., Schrandt, F., Gelmi, S., and Wojtkowiak, A., 2019, The instrument design of the DLR Earth Sensing Imaging Spectrometer (DESIS): Sensors (Basel), v. 19, no. 7, 1622. [Also available at https://doi.org/10.3390/s19071622.]

Ramaseri Chandra, S.N., Christopherson, J.B., and Casey, K.A., 2020, 2020 Joint Agency Commercial Imagery Evaluation-Remote sensing satellite compendium (ver. 1.1, October 2020): U.S. Geological Survey Circular 1468, 253 p. [Also available at https://doi.org/10.3133/cir 1468.] [Supersedes USGS Circular 1455.]

Teledyne Brown Engineering, 2021, DESIS_-Instrument: Teledyne Brown Engineering web page, accessed May 2020 at https://tbe.com/geospatial/instrument.

U.S. Geological Survey, 2020a, EROS CalVal Center of Excellence (ECCOE): U.S. Geological Survey web page, accessed May 2020 at https://www.usgs.gov/core-sciencesystems/eros/calval/jacie?qt-science_support_page_related con=3\#qt-science_support_page_related_con.

U.S. Geological Survey, 2020b, Landsat missions - Glossary and acronyms: U.S. Geological Survey web page, accessed May 2020 at https://www.usgs.gov/core-science-systems/ nli/landsat/glossary-and-acronyms.

For more information about this publication, contact:

Director, USGS Earth Resources Observation and Science Center 47914 252nd Street

Sioux Falls, SD 57198

605-594-6151

For additional information, visit: https://www.usgs.gov/centers/eros

Publishing support provided by the

Rolla Publishing Service Center 
